\title{
Never again. Health and sustainable development in the light of the pandemic. What went wrong?
}

\author{
Martin McKee \\ Department of Health Services Research and Policy, London School of Hygiene and Tropical Medicine, United Kingdom
}

ADDRESS FOR CORRESPONDENCE: Martin McKee, Department of Health Services Research and Policy, London School of Hygiene and Tropical Medicine, United Kingdom, e-mail: martin.mckee@lshtm.ac.uk

My title is health and sustainable development in the light of the pandemic. And my message is, never again. I'm going to be saying something about the lessons that we have learned from looking at what has been happening in Europe and to some extent further afield. To begin I'd just like to say that this is the summary of the work that has been done in the Pan-European Commission on Health and Sustainable Development. I have been very privileged to chair its Scientific Advisory Committee and also to be the main raporteur for the project. It's a project with a team that hasn't had many people with particular expertise in health on it, but this I think, is a good thing, it brings together two former prime ministers, Mario Monti and Helle Thorning-Schmidt from Italy and Denmark, three former presidents, and people from international banks and civil society and elsewhere. We just published our report a few weeks ago, and I hope some of you have had a chance to read it.

So, let's start by thinking about what went wrong; and here I'm going to draw on an analogy that several of us published in the British Medical Journal last year, where we likened a country in the midst of a pandemic to a ship in a storm, or more precisely a set of countries being like a fleet of ships trying to get through a storm. What went wrong, what do you need to get through to the calm water on the other side? Well, you need a captain with the ability to take decisions, to be decisive, to show leadership. Now if you look at the countries that have done worst in the world, you can see that we had serious problems. I'll just mention in passing Donald Trump, Boris Johnson, and Jair Bolsanaro, and you can see the problems that we faced. On the other hand, if you look at people like Jacinta Ardern you can see how things can go much better when you have somebody who knows what they are doing and can take a clear view as to what needs to be done. The captain of the ship needs to have a crew in sufficient numbers, enough people to raise the sails and to take them down when needed, and to move things around on the deck, who are working together, and who are adequately trained. The ships themselves need to be strong and secure. You need to have robust safety procedures, safety nets, so that you don't have people wandering around the deck and falling into the sea. You need to have a means by which the ships can communicate with each other, the countries can communicate about what they are doing, about their cases of disease, about the research that they are doing and so on. And you need to have a system of surveillance; you need to have a lookout to try to anticipate what is going to happen, the modellers, the people gathering data on the variants of the virus and so on. And crucially you need to have a map, and it must be the right map. Countries in the Asia-Pacific region had a map labelled coronavirus, after their experience with SARS in 2003. We in Europe were using a map called Influenza. So, as we get into the report, we have a section that looks at the legacy of the pandemic:

- health - continuing outbreaks, long COVID, mental illness;

- health care - new models of care (remote consultations, surge capacity, greater team working;

- education - a lost generation;

- the economy - IMF and others suggest we will bounce back quickly, but will everyone benefit;

- the built environment - improved ventilation, active transport, home offices;

- the nature of work - endless zoom...;

- the changing role of the state - strategic industries, supply chain management, individual rights and obligations.

These are the things we are going to have to think about going forward - the health consequences of con- 
tinuing outbreaks, of future pandemic, of new variants, the burden of long COVID in those countries that have had a high burden of acute infections; and the legacy of mental illness.

But we need to look at the new ways in which we will be delivering health care. This has changed remarkably; we are seeing tremendous innovations and new models of care, with remote consultations for example. But we are also recognizing that we need to have greater surge capacity and we have found new ways work together in teams and hopefully this will continue in the future.

We have a huge challenge of a lost generation of school children who have missed out on education at a crucial period in their lives and that will live with this in the future. They can expect to face problems all the way through their working lives.

We don't know what is going to happen to the economy. The IMF and others suggest we will bounce back quickly, but we are not sure that everybody will benefit.

We are going to see changes to the built environment. Already people are looking at ways to improve ventilation, which will have an impact on other respiratory viruses, but we are also looking at more people working from home.

The nature of work will change. We have all found that we don't need to make all those trips we once did, but we have also found the disadvantages of not meeting in person, and of being on zoom endlessly.

And then we have the changing role of the state. We are seeing governments retreating from globalization, with strategic industries and supply chain management. We are reassessing the ralationship between the state and the individual whenever people decide whether or not they will be vaccinated or whether or not they will wear face coverings for example.

In the report we are very clear that we need to make the case for health. Throughout the pandemic there has been a debate about whether health even matters - shouldn't we just be enjoying ourselves, why should we be restricting our lives just because some people are getting ill and dying. And there are many arguments for health; I am not going to go through them in detail but promoting health is the right thing to do. We should do unto others what we would want for ourselves. Health is a human right and our governments have agreed that it is on multiple occasions. We know that health is a driver of economic growth, as is education. People who are healthier contribute more in terms of participation in the labour force and productivity. Health is a factor in security. We invest in defence to protect our people from external threats; in the same way we should invest in public health, and we are increasingly recognizing the role of health in solidarity. Countries, communities that experience declining health create fertile ground for populist politicians who want to sow division.
We need to plan ahead, but what comes next? There are so many existential threats to humanity set out by the World Economic Forum and others. Anything can happen, from another pandemic, an asteroid strike or artificial intelligence out of control. So we need a comprehensive approach to try to make sense of all of this. What we have done is create a model in which we have put OneHealth at the centre, the health of humans, animals and the living environment - all superimposed on planetary health, both the things we can't control like the asteroid strike and the things we can control like the loss of biodiversity. And acting on the health of us, the animals and the living environment, we have things that make life better, including the prerequisites of health going back to the Ottawa Charter, peace, clean water, food, but also newer things like digital inclusion and access to justice, as well as the threats to health, the things that damage health which can be corruption or organized crime, or the commercial determinants of health, the tobacco industry, the alcohol industry and so on. So this is our model; it is in the report. I don't have time to go through it in detail, but you can see how we have OneHealth in the middle, acted on by the natural and anthropogenic elements of planetary health and all of these things that we don't want, the global bads, conflict, pollution, food insecurity, lack of shelter, disinformation, racism; and the good things: digital access, safe environments, housing, education, water and so on.

Biodiversity is our ultimate insurance policy. That's what we need if we are going to survive as a species. Within countries we need structures and incentives and a supportive environment for coherent cross-government strategies which build on the well-established principle of health in all policies. But we need the international organizations to work together - the World Health Organization, the Food and Agricultural Organization, the World Animal Health Organization, the United Nations Environment Program. These need to develop a shared understanding of OneHealth, to agree common terminologies and to create that international architecture.

COVID has exploited existing inequalities. If we look at the death toll in a country like England, we can see that it maps onto the index of multiple deprivation. And we know why. In those areas where people are living in multi-generational households, who are overcrowded, who cannot work from home, who have a life that is precarious, who face food insecurity and so on. So we need to heal the fractures that weaken our society. We need internationally comparable information systems that capture the many inequalities in health and access to care within and among populations. We need to identify those in society who are leading impoverished or precarious lives. We need to develop and implement policies that will give them security, the security that we know underpins good health. And we need to adopt explicit 
quotas for representation of women, because we have seen so often that the voices of women and other groups that are often marginalized or left unheard in society, are left out of the formulation and implementation of health policy. Innovation is absolutely key. I'm speaking to you from the United Kingdom, which has done terribly badly in the pandemic. But in the area of innovation it has done really well. We've had the RECOVERY trial, in which a high proportion of patients with COVID were entered into a series of trials and this demonstrated the benefits of giving people cortical steroids and also demonstrated that chloroquine was not effective as a treatment. It was the system that saw the development of the Oxford AstraZeneca vaccine, the OPENSafely study, where the data on patients with COVID was brought together to identify who was at the greatest risk and who wasn't, using observational data to generate hypotheses that could be tested by others.

So we need to have innovation at the heart of our response going forward and that means we need to have research with purpose. We need to be able to identify the gaps in research, the neglected diseases. We shouldn't have neglected diseases. The neglected populations, the communities that are left out of the clinical trials, the communities that we call hard to reach, when we really mean that we haven't tried hard enough to reach them. We need to fill these gaps, we need to work in partnership, we need to work with the private sector. The private sector has played a crucial role. But we should not have a situation where we are essentially paying twice, where the public sector is paying for the research that allows the innovation to take place and then the private sector is reaping the benefits. Mariana Mazzucato and others have talked about how we need to share the risks and the benefits between these two sectors. And we need to make sure that when we do innovate, we make a difference. We need to have learning systems that adopt innovation rapidly. There is no point in having a new piece of information that can save people's lives published somewhere but never taken up, or where there is no mechanism for a health system to get those ideas into practice.

This is another area where we should never be in the same situation again - intensive care units that were overwhelmed, staff that were burnt out, experiencing moral injury, where they felt guilty because they knew that they could not give people the treatment that they wanted to give them. These are scenes that we saw across many European countries in the early days of the pandemic.

So we need to invest in strong and resilient health systems. We need more money for the systems, but we can't just pour money into it, we need to make sure that the money is spent appropriately, and that means strengthening and investing in the health workforce. Some countries, like the United Kingdom, thought that they could build hospitals rapidly, the Nightingale hos- pitals. Take a conference centre and fill it full of beds and ventilators. But that's completely pointless if you don't have the staff there, and you cannot just go down to the local labour exchange and find trained skilled staff if you haven't invested in training them to begin with. We need to work hard to bring health and social care closer together. In many countries we saw the Cinderella area of social care just ignored and as a consequence we saw people essentially being left to die, with COVID going through care homes, residential facilities looked after by staff being paid very little and who had inadequate supplies of personal protection equipment. And we need to prioritise prevention, because we know that it was those people with complex chronic diseases like diabetes that were most vulnerable when the pandemic came. And all of these things are great ideas, but how do we make them actually happen? Well the first thing we need to do is to create an environment that promotes investment in health. Too often when health ministers go to their finance ministries or when governments go to international finance institutions like the IMF, they are told off for spending money on health. And yet we now see that it is far more expensive if you haven't invested. So we make proposals to change accounting systems to promote investment, to incorporate health and health risks into economic forecasts, to include health when we are assessing the financial resilience of a country. A country cannot claim to be resilient financially, to have all the systems right in its banking system if it is weak in terms of its ability to resists a pandemic. We need to support investment in global public goods and we need to increase the share of development finance spent on health. We develop these ideas much more in the report. And we do the same with another set of recommendations where we talk about how we can improve health governance at the global level. We are proposing a global health board under the auspices of the G20. Why the G20? Because that's where the money is. We are basing this idea on what happened after the financial crisis which led to the G20 being created and it created a Financial Stability Board. And this Board was able to demand that central banks were prepared for a financial crisis, that they had invested, that they had liquidity. And one of the consequences of this was that during the pandemic we didn't have a global economic crisis, which could easily have had. And the Financial Stability Board liberated the necessary money when it was needed, which made it possible for the banks to be recapitalized. That was crucial, but when it came to health, well, yes governments did find money, but it would have been made much easier if we had had a global mechanism in place, and that's what we are calling for. We need a pandemic treaty, I think everybody agrees with that, but this is one that holds governments to account at the same time as supporting those in need. It is the fundamental principle that each should contribute according to their 
ability and each should be supported according to their needs. And we need a global pandemic vaccine policy that enables availability of vaccines for everyone and also that those vaccines can get from the laboratory into people's arms so that they actually make a difference

So my concluding thoughts are that we have set out a very ambitious agenda; we know that it's not going to be easy but if is going to work countries will have to accept shared sovereignty for the greater good. Now you think why would they do this, but they already do it in many areas; they do it for nuclear and biological weapons, they do it in international finance. There are much stronger regulations against counterfeit banknotes than against counterfeit medicines. They do it with the law of the sea, so all we are asking them to do is to take the same sort of measures when it comes to health. So that they come together to protect us all wherever we live on this planet, the only planet we have, because we will have more and more threats and in particular those that are arising from what we are doing to this planet. And we need to be prepared next time, so that we really can come out of this and say to ourselves "never again".

\section{DISCLOSURE}

The author reports no conflict of interest. 